\title{
SSIEM 2011
}

\author{
Nenad Blau • Brian Fowler
}

Received: 15 May 2012 / Accepted: 15 May 2012 /Published online: 19 June 2012

(C) SSIEM and Springer 2012

There is no doubt that early detection of inherited metabolic diseases and prompt and continuous intervention prevents mental retardation in many patients. Unfortunately, there is no consistent screening policy for newborns worldwide and for a number of diseases there is still no adequate treatment. Nevertheless, even in the last-mentioned group of patients early diagnosis may improve the quality of life and expectations. Thus it was opportune that "Newborn Screening and Inborn Errors of Metabolism" was the topic of the joint meeting with the International Society for Newborn Screening held as the opening session of the 2011 Annual Symposium of the Society for Study of Inborn Errors of Metabolism (SSIEM) in Geneva which took place from August 30 to September 2. in the city of Geneva, an ideal location with its truly cosmopolitan flavour, set between mountains and the lake.

The SSIEM Annual Symposium was organized locally by the Swiss Group for Inborn Errors of Metabolism (SGIEM) and the main topics reflected interests and traditions of the Swiss metabolic community. These topics were "New Concepts in Vitamin Responsive Disorders", "Creatine metabolism", "Adult Metabolic Diseases", and "Gene Therapy of Inborn

Communicated by: Verena Peters

N. Blau

Division of Inborn Metabolic Diseases,

University Children's Hospital,

Zurich, Switzerland

N. Blau $(\triangle)$

Division of Inborn Metabolic Diseases,

University Children's Hospital,

Im Neuenheimer Feld 430,

69120 Heidelberg, Germany

e-mail: nenad.blau@med.uni-heidelberg.de

B. Fowler

Metabolic Unit, University Children's Hospital Basel (UKBB),

Basle, Switzerland
Errors of Metabolism". A comprehensive range of other areas of inherited metabolic disorders was covered in 12 workshops containing free communications as well as the poster sessions, with a total of 689 submitted abstracts and hot topics were presented in the "Late Breaking News" session. The record attendance of over 1700 participants proved the attractiveness and topicality of the programme. The scientific highlights of the symposium were the "Komrower Lecture" given by Marie T. Vanier and based on her life-long achievements in the field of lysosomal neurolipidoses and the Archibald Garrod Award for the best clinical study published in 2011 the Journal of Inherited Metabolic Disease (JIMD) which was received by Frits Frijburg for the study entitled "Mucopolysaccharidosis type IIIB, attenuated clinical phenotype". Highlights of the social programme were arguably the best-ever conference party with excellent food and entertainment until late in the night and an afternoon outing to the unique CERN.

This issue of the JIMD includes selected papers of plenary presentations during the 2011 meeting. In particular five papers cover the latest developments in Newborn screening, namely two on efforts towards harmonization in Europe, screening for cystic fibrosis, ethical aspects of screening for lysosomal storage diseases and the potential and pitfalls for clinical use of whole genome screening. Three papers illustrate latest ideas for gene therapy with experience in two specific disorders. The remaining three papers provide authoritative reviews on creatine transport into brain, folate disorders and disorders involving riboflavin and Coenzyme Q10.

We would like to thank all members of the Swiss Group for Inborn Errors of Metabolism, SSIEM council members, and sponsors for giving us the opportunity to organize such an unforgettable event.

Conflict of interest None. 